\title{
Chapter
}

\section{“AlWAYS THERE": How DiPlOMATS DEAL WITH VISIBILITY INJUNCTION IN THE DIGITAL Public Sphere}

\author{
Nadège Broustau, PhD* \\ Research Center on Information and Communication (ReSIC), \\ Department of Information and Communication Science, Free University of \\ Brussels (ULB), Brussels, Belgium \\ Marie Neihouser, PhD \\ Research Lab on Political Communication (GRCP), Laval University, \\ Quebec City, Canada
}

\begin{abstract}
This chapter focuses on the required use of social media by diplomats and aims to understand how they operationalize this strong but blurred injunction from their hierarchy. Participating in conversations, debates and engaging with the public, giving opinion, showing pictures or videos, sharing or commenting news or anniversaries, the concrete interpretation of the visibility injunction can take various forms that may be close or quasi antinomic to the essence of social media. Secrecy and caution are especially part of the decision process of publishing content on social media, leading diplomats to try and find a balance between constant visibility in the public sphere and protection of sensitive issues. Based on interviews with several diplomats in Brussels, Paris and Kiev, in particular public affairs officers in embassies as well as in missions to the European Union, our chapter draws their representation of the social media communication constraint, how they include or not evaluation and reflexive steps in their practice, what expectations
\end{abstract}

*Nadege.Broustau@ulb.ac.be

*Neihouser.Marie@gmail.com 
they figure their hierarchy, colleagues, partners, adversaries, citizens have and how they cope with these expectations.

Keywords: Digital Diplomacy, Social Media, Digitalization, Communication Injunction

\section{INTRODUCTION}

This chapter focuses on the required use of social media by diplomats and aims to understand how they operationalize this strong but blurred injunction from their hierarchy. Digitalization has indeed led diplomats to be exhorted to openness, at least from the perspective of showing parts of their daily routine to the public. As go-between nodes in the public sphere and in the media landscape, social media have become usual tools that diplomats are enjoined to use in order to achieve the general mission of being present in the public eye.

But as Wichowski put it, "information-sharing culture and the preservation of sensitive information are inextricably linked" (2015: 54). Secrecy and caution are thus part of the decision process of publishing content on social media, leading diplomats to try and find a balance between constant visibility in the public sphere and protecting of these sensitive issues from public scrutiny. Though social media use is originally characterized by interaction, sharing and appropriation (Proulx, Millerand and Rueff, 2010), in the public diplomacy context, what seems to be firstly asked from diplomats is to be present in the digital sphere. Participating in conversations, debates and engaging with the public, giving opinions, showing pictures or videos, sharing or commenting on news or anniversaries..., the concrete interpretation of the visibility injunction can take various forms that may be close or quasi antinomic to the essence of social media.

As Archetti's work tended to show, "[d]igital technologies have increased an embassy's ability to communicate with foreign populations, create relationships with key audiences and elites, and manage their nation's image" (Archetti, 2012, in Manor, 2019: 290). According to Manor, the digitalization of public diplomacy has given back power to embassies, "embassies [that] have reasserted themselves in the diplomatic field" (2019: 290). Social media may then participate in the management of the nation's image but also to the management of the embassy's image as a distinct institution. We assume that embassies have to deal with a paradoxical position on at least two levels: 1) they must reconcile a duty of discretion and digital 
"Always There": How Diplomats Deal with Visibility Injunction in the 3 Digital Public Sphere

visibility injunctions, including social media engagement, though engagement has appeared as a limited and unfinished tool for public diplomacy (Cull, 2013; Pamment, 2015; Kampf, Manor, Segev, 2015) and 2) they are "guests" in a foreign land, where they have to act as representatives of their government, embodying its values on an international scale, but where they also have to build a specific identity for local publics, on national and local scales.

Based on interviews with several diplomats in Brussels, Paris and Kiev, in particular public affairs officers in embassies as well as in missions to the European Union, our chapter draws their representation of the social media communication constraint, how they include or not evaluation and reflexive steps in their practice, what expectations they figure their hierarchy, colleagues, partners, adversaries, citizens have and how they cope with these expectations.

\section{Theoretical Background}

Over the past decade, more and more governments have encouraged their diplomatic agencies to use digital tools (Criado and al. 2013, Righton 2013), leading to an injunction of digital presence. Although these practices of online diplomacy are studied, the issues of communicational professionalization from the point of view of media sociology and political communication remain to be documented and understood. Indeed, it seems essential to understand how diplomatic actors respond to this constraint of online visibility and online presence that contribute to the shape of international diplomacy balance.

The spread of digital disinformation (Bjola and Pamment 2018), the development of new trends (AI, augmented reality, etc.), and the growing demand for digital training have put additional pressure on embassies and Ministries for Foreign Affairs to refine and improve their digital profiles and strategies (Seib 2016, Owen 2015). In this context, a new field of research has been developing, on the boundary between diplomacy and public relations: its goal is to study the use of digital and social networks in public diplomacy (Sevin and Manor 2019, Zhang 2013, Glassman 2008, Vergeer and Hermans, 2013, Wigand 2010, Kim 2015, White and Racic 2014, Su and Xu 2015, Park and Lim 2014). Most of these studies focus on analyzing the content of messages published by the various government institutions (Dodd and Collins 2017, Straub et al., 2015, Zhong and Lu 2013). The aim is then to demonstrate the public's reasons for interacting with foreign governments (Khakimova 2013), to study the efforts of governments to reach this audience (Zhong and $\mathrm{Lu} 2013$ ), or to demonstrate usefulness of social networks to address stakeholders (Waters, Burnett et al., 2009). 
In Europe, the core studies on digital diplomacy are provided by researchers like Bjola (Bjola and Holmes 2015) and Manor (2019) who are engaging in a large work of theorization of public diplomacy (Entman, 2008). However, their work aims to theorize public diplomacy but not to understand professional upheavals and broader issues of communication. Until 2015, some authors pointed out the gaps of this kind of study: the focus on the US case to the detriment of the rest of the world in the choice of case studies (Gilboa 2008), the lack of systematic quantitative (Zhong et al. Mon 2013) and comparative (White and Radic 2014) studies on the subject, the gap between theoretical vision and actual implementation of social networks (Criado et al 2013, Meijer and Thaens 2010, Fisher 2010), or the nonestablished role of digital and social networks in achieving the objectives of diplomacy (White and Radic 2014, Yepsen 2012). The field is now better structured, at least in an English-speaking context.

The francophone environment has indeed been poorly studied. Most of the French publications on the subject deal with public diplomacy of non-French speaking countries, notably Russia (Limonier and Audinet, 2017), USA (Nocetti, 2011, Ricaud, 2018) or China (Huang and Arifon, 2018). Others are the product of international relations researchers and not communication researchers (Gomart, 2013) and thus do not focus on communication professional skills nor do they use the sociology of media or political communication literature to explain the process of professionalization or editorialization for example. The purpose of our contribution is precisely to better understand the production processes of this new public diplomacy in a Francophone environment. To do this, we focus on the online public diplomacy of the members of the Organisation Internationale de la Francophonie - International Organization of la Francophonie (OIF) created in 1970 and which brings together 88 states with very heterogeneous diplomatic resources.

\section{METHODS}

\section{Main Goals and Research Question}

Our core question is how embassies do operationalize the permanent but often unclear injunction to be present on the social media that they receive from their hierarchy - Ministries of Foreign Affairs or chiefs of government. We thus wanted to understand how embassies' diplomats comprehend the need to create, fuel and sustain social medias and how they deal with this demand in their daily routine. 
"Always There": How Diplomats Deal with Visibility Injunction in the 5 Digital Public Sphere

Two assumptions guided our analysis, as we took into account that embassies face a paradoxical position on at least two levels: 1) they have to balance secrecy with openness linked to the digital public presence and 2) they have to represent their government as well as build their specific institutional identity in the foreign country that hosts them. This paradoxical position takes place in a context of audience superposition, as embassies may target local and international audiences, both on national and local scales. This communication challenge thus needed to be addressed as well in our work.

\section{Interviews as Exploratory Tools}

To access the experience and point of views of the actors, we privileged an inductive and comprehensive approach based on semi-structured interviews. In parallel with the interviews, we used an analysis grid of the social media used by the embassies so as to determine their effective presence on the "digital public stage". The principal aim of the interviews was then to collect data about the way diplomats experience, understand and apply the digital public presence demand.

Interviews were conducted as an exploratory step in order to tackle three dimensions of our research question:

- The representation of the social media communication presence by diplomats: this dimension implies an understanding of how the actors consider this presence, in particular how they see this presence as a constraint and what kind of flexibility they dispose of. Questions about the validation chain regarding the content published on social media, the balance between openness and duty of discretion and the resulting consequences for time and resource management were notably asked in this perspective.

- The expectations they figure their hierarchy, colleagues, partners, adversaries, citizens have and how they cope with these expectations: this dimension revolves around the knowledge diplomats have about their audience on social media- who follows them and to what purpose -, the mediathey judge the most relevant to meet these expectations and the content - including interaction - they regard as the most attractive (including from a personal point of view) or adequate in order to respect the needs of the public.

- The reflexive steps taken in their practice: this dimension includes the use of evaluation tools as well as debriefings or social media and communication trainings the diplomats may initiate or be offered. It also implies the strategic goals that may emerge from reflexive steps, in particular concerning identity and editorial issues. 


\section{Field of Research: from Brussels to Kiev}

We first chose to focus on the embassies of all the 88 OIF members based in Brussels, since we wanted to look at how they have to simultaneously adress the digital presence in a foreign country, Belgium, but also in the heart of a multicountry entity. This choice was made in order to tackle the communication challenge of superposition of targeted audiences we wanted to adress. We chose to interview primarily public affairs officers in embassies as well as in missions to the European Union.

Prior to the interviews, we began by checking and classifying the social media used by the embassies of the 88 OIF members so as to determine their public online presence and visible digital uses. We checked if they had social media accounts on Twitter, Facebook, Instagram and LinkedIn - social media accounts of embassies and social media accounts of ambassadors themselves -, when were the accounts created, how many followers they had, how many accounts they followed and what were the profiles of their followers and their followees.

We began by conducting interviews with the embassies of Canada, Switzerland, France, Luxembourg, Burkina Faso, the Republic of Benin, Morocco, Haiti, Vietnam, Ukraine, the General Delegation of Quebec in Brussels and the Mission of Switzerland to the European Union. Though we initially planned to focus on diplomatic institutions based in Brussels only, these interviews led us to complete the data of some of them with additional interviews with embassies in Paris (Republic of Benin) and to move our focus to another context, Ukraine, where diplomats pointed out they had to face a different kind of reality regarding the use of social media as public diplomacy tools (Canada, Switzerland, Belgium, France, Morocco). This snowball sampling method enabled us to observe two very contrasted ways of dealing with the visibility injunction in the digital public sphere: a social media ordinary use versus a social media priority use.

\section{EMbASSIES IN BRUSSELS (AND PARIS): SOCIAL MEDIA "ORDINARY USE"}

Though literature seemed to point out the generalized use of social media as being part of public diplomacy, our first analysis of social media presence by the OIF members showed that it is far from being the case systematically. For instance, on a first sample of 15 members from the 6 continents out of the 88 members of the OIF (Burkina Faso, Canada, France, Haïti, Republic of Benin, Luxembourg, 
"Always There": How Diplomats Deal with Visibility Injunction in the 7 Digital Public Sphere

Marocco, Quebec, Switzerland, Tunisia, Ukraine, Vietnam, Lebanon, Cameroon, Vanuatu), only 8 embassies are present on Facebook and 7 on Twitter (6 are present on both social media). There is no embassy on Instagram neither on Linkedin. Furthermore, from this sample, only two ambassadors have a Twitter account.

Among those that have a presence on social networks, there are also differences according to the number of followers and likes. On Facebook, the page the most followed is the Ukrainian page (4625 followers), followed by the Haitian page (4513 followers), the French page (3802 followers), the Quebec page (3728 followers) and the Burkina Faso page (2237 followers). The three less followed pages are the Cameroon page (459 followers), the Luxembourgish page (414 followers) and the Tunisian page (210 followers). It is interesting to note that the distribution of the 'like mentions' follows the same order.

On Twitter, the distribution is different: the three most followed are the Quebec representation (3483 followers), the Canadian Embassy (2582 followers) and the Ukrainian Embassy (1221 followers). The three less followed are France (190 followers - although the French Ambassador has 1066 followers), Lebanon (108 followers and Cameroon (45 followers).

But there are also differences according to the date of creation of the accounts. The first account created on Facebook is the Quebec page (2010), followed by the French (2012) and the Haitian pages (2013). The last Facebook pages created are those from Tunisia (2018), Burkina Faso (2017) and Marocco (2017). The first embassy to be present on Twitter was Quebec (2010) and the last three are France (2015), Luxembourg (2017) and the French Ambassador (2015). From this first point of view, the 'traditional' order of diplomatic presence seems not to be reproduced - e.g. delay of France to arrive on Twitter or high numbers of followers for the Haitian page

These digital disparities are clearly confirmed by the interviews with the actors. While we did not confront them with the data we had observed in the first exploratory step, all of them enhanced, on various levels, disparities and sometimes tensions between what they feel they are supposed to do, what they can really do and what they would like to do.

\section{From the Differences of Human Resources to the Differences of Practices: the Heterogeneity of the Online Presence}

Some of the above embassies or missions studied have a genuine communication service that include full-time communication officers (Canada, Quebec, France). But none of them employs full-time community managers. In fact, most of them face a shortage of human resources in this area. For example, some 
countries choose to mutualize their communication resources between their embassy and their national representation mission to the European Union (case of Switzerland). Others are supposed to employ communication officers who actually turn out to be political advisors (Republic of Benin, Burkina Faso). In this case, the function of the communication officer is larger than the communication area. Furthermore, most of the time, he or she doesn't have specific digital communication skills. For instance, having a Masters degree in political science and in international relations plus a Masters degree in political communication, the Policy and legal Advisor of the Benin Embassy in Paris in charge of the digital communication of his Embassy presents more a diplomatic profile than a digital communicator profile (no specialized training in digital communication). He is in charge of the communication of the Embassy - among other tasks - with his assistant and some trainees. The Burkina Faso Embassy in Brussels, for example, has a communication officer since only two years. As a former journalist at the national information agency (Agence d'information du Burkina) and graduate in geopolitics, the digital communication field is totally new for him. This nonspecialization can be harmful in some cases. The digital communication officer of the Burkina Embassy in Brussels says he found himself "totally technically deprived when [he] realized that someone other than [him] had managed to publish on the Facebook page of his Embassy when [he] was supposed to be the only one to have access".

These disparities and this lack of human resources is also to be found in online practices. The description of the time management by the people in charge of the communication testifies to the non-priority status of digital communication in most embassies. Whereas some communication officers declare spending 4 to 5 hours per week to the digital communication of their embassy or even to use them almost every hour (including during their personal time), others can't evaluate the time they spend on it - digital communication being of a very secondary importance for the embassy. In the same way, many of them declare to not practice a systematic watch of the online contents. This watch is then broken out between the different services of the embassy (economy, culture, etc.) that leads to a sporadic watch "when they have time".

This non-priority is also reflected in the fact that the validation chain for publications is remarkably short. Total autonomy is left to the embassies on this point. Ambassadors have the last word to validate or not the publications. This leaves a relatively large flexibility for the persons in charge of the communication, a margin of maneuver that they must combine with the restricted resources they have. 
"Always There": How Diplomats Deal with Visibility Injunction in the 9 Digital Public Sphere

In these conditions, the online presence of embassies often comes down to public service missions to national citizens living in the host country or for the citizens of the host country that want to visit or to immigrate in the country of the embassy and to promotional writing. Promotional writing aggregates different activities: commemorations, links with the host country, common struggles, exaltation of the beauties and attractions of the mother country (for the tourist), and of the host country. Therefore, the challenge is to find words that are sufficiently original and the least repetitive possible to flatter the different interlocutors.

The communication officer from the Benin Embassy in France explains that the goal of the online presence of his Embassy is to promote Benin destination especially for tourism and international investments. But he notes that the online presence also allows citizens to mobilize for Benin, as is the case in the ongoing negotiations with France for the restitution of cultural property in Benin that it holds because of colonization. Another example of mobilization was experimented with the kidnapping of two French tourists in Benin in May 2019, in particular to counter the media hype that this kidnapping has caused in France for its detrimental repercussions on the tourist attractiveness of Benin. He also evokes how storytelling is especially used to enhance the personal action of the Ambassador, a common point with most of the participants we interviewed.

Mobilization or awareness can also represent the ultimate goal of social media communication. For instance, to the diplomat in charge of social media - as well as scientific cooperation and cultural events - at the Embassy of Ukraine in Brussels, social media are a tool to "promote my country in order to let know what happens in Ukraine and to engage [Belgian citizens] a little bit", notably regarding the issue of Ukrainian prisoners.

\section{To Be Attractive: How Estimated Expectations Shape the Online Presence}

The online presence highlights the embassy's action in relation to the governmental priorities. In a context where the usefulness of diplomats is always questioned, the online presence allows above all to demonstrate the variety and diversity of activities of the embassies that cover a growing spectrum: representation, negotiation, economic and cultural action, protection of expatriates, tourism, cultural and economic promotion, social action, etc.

Although they allude to examples of accounts that they know are part of their followers, diplomats interviewed describe an intuitive knowledge of their audiences as they do not dispose of evaluation tools nor time to use them. But even if the representation of the audience they target (and actually affect) remains relatively 
vague for the communicators, there is a relative dichotomy between the content posted on Facebook and that published on Twitter. Thus, Facebook being more seen as the medium that allows to communicate with expatriate nationals, it is rather used for cultural and social purposes, in the promotion of events, etc. Twitter is, however, favored when it comes to targeting opinion leaders (journalists, other embassies, host country authorities, interest groups, etc.).

In other words, by targeting (often not really knowing if they really reach them) different audiences via two major social networks (Facebook and Twitter), embassies we studied are adopting online the 'catch-all' strategy to appeal to as many people as possible, a way for them to limit the risks of an online presence that they are still struggling to grasp.

The 'good post' is then the one that collects both the most mentions "I like", the more shares and the more positive comments. For example, a communication officer explains: "Every month, the Facebook page of the Embassy has an average of 200 new subscribers and some of these publications are widely shared, evidence of its growing influence. The goal is to reach 10,000 subscribers by the end of 2019 ". If this quantitative goal is a clear landmark, it is nevertheless worth noticing that it has been decided on an arbitrary basis, without evidence or knowledge of what is supposed to be an efficient number of subscribers nor what kind of subscribers will be targeted.

\section{Latent or Inexistent Reflexivity?}

No method of systematized evaluation of their impact or influence online was indeed mentioned by interview participants. Once again, it should be noted here that digital communication remains a secondary activity in most embassies that do not yet have adequate resources and communication resources. At this stage, the digital communication of certain embassies is thus more of a personal initiative, for instance of each of the communication officers, sometimes under the influence of their ambassadors, than of a long-term state vision.

Under these conditions, a unified vision of the objectives of an online presence of embassies remains to be built. In this context, it is then difficult to imagine that common rules can emerge, so as to come to 'normalize' online practices - notably because of the very different presences and uses depending on the resources available to the actors.

However, some embassies can be more reflective or organize common tools to pave the way for establishing best practices and guidelines. For example, the social media coordinators of several embassies in Brussels, including Ukraine and

Canada, meet monthly in order to discuss their experience and sometimes 
"Always There": How Diplomats Deal with Visibility Injunction in the 11 Digital Public Sphere

coordinate or engage together in social media publications, like sharing the \#saveOlegSentsov hashtag for the release of the Ukrainian film maker. In another local initiative, the Canadian Embassy in Brussels organized in 2017 an internal seminar about diplomacy and political communication, during which were especially discussed the relevance and the management of the digital tools with an academic scholar invited. This space for exchange was an opportunity for the members of this embassy to reflect upon the public debate about the negotiations for a comprehensive economic and trade agreement (CETA) between the EU and Canada during which Canada was the subject of harsh criticism on social media, in particular from European citizens or organizations. In this time of crisis, the question of public participation in the digital public sphere became crucial: should an embassy intervene in the debate to correct what it judges as disinformation or moderate information? Should it let the "bad buzz" go on and disappear by itself given the very fast tempo of buzz and news on the social media stage? Having no guideline to face this kind of situation, the Canadian diplomats had to try and trust their instinct, in this case stepping back from the online criticism and bashing that occurred. This case led us to look at the influence that digital diplomatic communication could have in times of crisis and, conversely, at the influence a crisis context could have on the social media use by diplomats. Given that when the stakes become more 'important', the positions of embassies regarding their digital communication could potentially differ, we decided to complete this study by analyzing the digital communication of different embassies in a country under pressure, in the process of democratic transition: Ukraine.

\section{EMBASSIES IN KIEV: SOCIAL MEDIA PRIORITY USE}

We considered using another diplomatic context aimed at exploring in a more contrastive way how embassies interpret their social media presence duty. As the case of Ukraine was evoked in several of our encounters and constituted a sensitive context, we applied our analysis grid of the social media (mainly Twitter and Facebook) of the embassies of the OIF members in Kiev and asked for interviews with a sample of these embassies - Canada, France, Switzerland, Belgium and Morocco. The social media presence of the embassies located there tends to be much more limited than the one of embassies located in Brussels. Out of the same sample of 15 countries we used for our first step of observation of social media used by embassies in Brussels, only 3 embassies in Kiev have a Twitter account, 5 a 
Facebook page, the 3 on Twitter being also on Facebook, with 2 of them - France and Canada - having their ambassadors using an individual Twitter account as well. In spite of this limited presence at first sight, the number of followers and like mentions are much more important than what we observed for embassies in Brussels.

On Facebook, the three most followed pages are the one of Canada (22702 followers), France ( 7080 followers) and Switzerland (2741 followers). These three embassies are the only ones of our sample also present on Twitter with 6771 followers for Canada, 2600 for France and 2054 for Switzerland. Regarding the time they began to have a social media presence, France was the first to create a Facebook account in 2013, followed by Canada in 2014, Belgium in 2015, Switzerland in 2017 and Morocco in 2018. France was also the first to create a Twitter account in 2014, followed by Canada the same year, and Switzerland in 2016. Parallel to these official accounts, 2 ambassadors have individual Twitter accounts, Roman Waschuk, Ambassador of Canada in Ukraine, and Etienne de Poncins, Ambassador of France in Ukraine. While the French Ambassador has 1015 followers and has posted 106 tweets since his account creation in 2012, the Canadian Ambassador has 10200 followers and has posted 27400 tweets since the creation of his account in 2014. As interviews revealed later, the Canadian Ambassador is the most active Canadian diplomat on social media worldwide, an appropriate feature regarding the Ukrainian context.

This quick overview of the diplomatic social media landscape allows a glimpse of what strongly emerged from the interviews, that is that the conception of social media and how to manage them is characterized by an accurate awareness of the lively use of social media specific to Ukrainian society.

\section{To Hear and to Be Heard: Contrasted Embodiment of A Key Presence}

Whatever the effective presence they have been able to implement on social media for the moment, the diplomats we interviewed all underline that social media are for them a key access to the local political sphere in Ukraine. This access is seen as a key to be heard from as well as to hear what occurs in the political sphere of the host country. The interviewee at the Swiss Embassy in Kiev highlighted "I was surprised how much social media were being used when I arrived here. I had to seriously get started with it, because in the other embassies I used to work, digital communication existed but remained a bit "passive". Here, in Ukraine, social media are a very important channel: the Embassy of Switzerland [...] has to communicate a lot. Yet Ukrainian authorities react very quickly via social media". So the Embassy sends out messages on social media about "our positions, what we 
"Always There": How Diplomats Deal with Visibility Injunction in the 13 Digital Public Sphere

find right, or not, what we commend or what we condemn". Beyond this space of action-reaction with national authorities, the chief of political and public affairs section of the Canadian Embassy pointed out, "[a] lot of Ukrainian politicians use Facebook to give their political comments. So I have to follow them to know what they think". The interview participants evoke the influence of the Maïdan revolution of 2013-2014 on the development of this lively online public sphere. "The civil society and the journalists got organized online. Digital environment has thus become an official media to communicate with the officials" insists the Swiss diplomat.

If the importance attributed to the online presence of embassies appears as a consensus among the participants in our study, the resources to manage this presence are, like in Brussels, a stumbling block in the way towards a clear professionalization of digitalized public diplomacy. Communication skills are indeed mingled with political, administrative and economic ones, if not drowned by them. For instance, though the Embassy of Belgium in Kiev has a Facebook page, their Consul mentions they work with a pared-down crew, having no one officially in charge of communication nor digital media. The same situation is faced by the Swiss Embassy. Despite a quite active presence on Twitter and Facebook, they "are not big enough [30 persons] to have someone devoted to communication". Thus, the Ambassador tweets directly, or he validates an idea of content and the person in charge of the service (culture, economy) tweets by herself. At the Embassy of Canada, a part-time communication trainee helps the public affairs team for media relations, including social media. The French Embassy is employing a young communication officer ('administrative international volunteer') helped by a trainee. These two resources are supposed to be supervised by a political councellor but, this councellor having too much work with the political part, the communication officer is the real coordinator of the communication of the Embassy. As she says, in Kiev, "the French Embassy is a little Embassy [according to the number of employees], but with high ambitions [from a political point of view]".

The validation chain then also varies in function of the available resources. The interviewees all report that they do not receive a centralized guideline from their Minister. Moreover, in every case, the ambassadors validate the content or at least the original ideas of the messages that are going to be published. At the Embassy of Canada as well as in the Embassy of Switzerland, each sector (culture, economy...) proposes some ideas of message that are being validated or not by the Ambassador. Both chiefs of sectors and ambassadors thus have the task to take care of the editorial line of their social media. This flexibility, that implies an additional workload to their role, is however sometimes framed by clear rules. For instance, the Canadian Embassy can not retweet tweets that come from Canadian ministers 
or the Prime minister. This rule stems from a will to separate politics and diplomacy.

Specific editorial lines identified by the actors between social media carry specific rules too. Facebook is seen as a more social platform, leading to mere cultural content, while Twitter is seen as a place to express "political positions since journalists, think tanks, other embassies and opinion leaders are there" explains the Swiss diplomat. This dichotomy entails some issues and choices: "Facebook is a challenge, because you normally have to write a normal full text and we don't have time for that. [Thus] Twitter better reflects what we do" tells the Canadian participant.

The lack of time appears as the main latent pressure felt by the diplomats. The digital watch management shows this puzzle situation, with efforts from the diplomats to watch social media of other foreign embassies, Ukrainian NGOs and authorities, but without an active watch team. Here again, each person in charge of a sector watches when she has time.

This pressure is all the more blatant since beyond communicative practices, the online presence of these embassies also implies that the communication officers - or the various persons in charge of communication tasks - find the way to seize social media as communication tools to convey certain messages much in touch with traditional issues of diplomacy.

\section{To Be Appropriate: How "Noble" Diplomatic Expectations Frame the Online Use}

The digital presence seems paramount in, like the Canadian diplomat put it, a "noble" diplomacy perspective, and a delicate balance has to be found in order to "influence without interfering". Far from a simple anecdotic presence, "a tweet is like a foreign policy stamp of approval or disapproval", adds the same participant. "Official statements of encouragement" are therefore a preferred approach, and "they have an impact". The official welcome of the creation of the High AntiCorruption Court of Ukraine (HACC) in April 2019 on the social medias of embassies in Kiev is mentioned as an example of this dynamic of supporting a policy evolution, in this case, a step towards democratic transition. For publicly approving such a policy move by the government of the host country means also supporting local people that may be concerned by this policy move.

Social media are seen as an element of a diplomatic combination that includes off-line traditional tools like meetings, an element that may nevertheless constitute a strong way to emphasize traditional diplomatic positions. In Ukraine, notices the participant of the Embassy of Switzerland, "you have sometimes to complement the traditional diplomatic work by making some things more public [that is online]". The embassies here tend to uphold ideals and causes of their country more 
"Always There": How Diplomats Deal with Visibility Injunction in the 15 Digital Public Sphere

than they promote selling arguments for their country, effectively acting on what is qualified as a "noble" diplomatic level (Carta, 2012).

In this context, a collective game and negociation on the social media stage seems to take place between embassies, either prepared or spontaneous. The "Twitter account of the French Presidency of the G7 Ambassadors' Support Group in Kyiv"(@G7AmbReformUA) illustrates how embassies in Kiev strategically coordinate their communication efforts to support policy evolution in the host country. But the communication officer of the French Embassy - who was in charge of the account during the French presidency - explains how it is hard for diplomats to reach a consensus concerning the content of tweets: "For one tweet of 280 characters, you have to deal with 50 e-mails". She also points the fact that this necessity of coordination about 'noble' diplomacy elements, which takes time, is particularly not adapted for the social media norm of instantaneity. On a less prepared level, the Swiss participant describes that "[w] hen several countries play a role in a reform project, for example the health reform [...], if there are attacks against the reform, for example some people trying to sabotage it, sometimes we coordinate [with other embassies], saying "ok, it would be good to tweet something, to condemn if there are some kinds of blockage". This can happen several times per year". He also precises that as soon as issues related to conflict, security or OTAN are concerned, the Embassy stays back, in accordance with the traditional diplomatic positions of Switzerland. The Canadian diplomat also points out the important role played by embassies to uphold causes like the LGBTQ rights (Gay Pride), the Human rights, the Humanitarian law. Embassies like France or Belgium are also part of spontaneous digital alliances that work by retweeting and sharing content posted about these issues. "Being spontaneous" or appearing to be spontaneous through the content posted on social media precisely appears to be a challenge identified by some diplomats, leading to a tension between "on the spot" publication and strategic planning.

\section{Latent and Wishful Reflexivity}

The tension between spontaneity and strategy is highlighted in the latent and wishful reflexivity evoked by some of the interviewees. Whereas some monitoring tools are initiated by or offered to some of the embassies' teams we interviewed, the reality of their daily routine relegates communication improvement to the background. The case of Canadian Embassy is very interesting from this point of view. For example, the Canadian Embassy received an inspection team from Ottawa in November 2018. The latter gave them the following observation: admittedly, the embassy is very active online, however, it does not have a real online strategy. "The embassy staff are aware of this lack", admits the Canadian diplomat, "but we lack time to do this" he deplores.

The same problem of wished but unfulfilled communication upgrading occurs regarding the strategic comprehension of audiences or the strategic use of the social 
media to its full potential. For instance, the same interviewee recalls "we followed an Advocacy and social media training. In this formation, the emphasis was placed on the fact that it is absolutely necessary to determine our target audience versus non-targeted audience. However, in practice, we don't have the time to do this". They had also thought about creating Instagram and Youtube accounts but do not have sufficient human resources to complete the project. In the same strategic ideal, they had also prepared a social media publishing plan 2 years ago with representatives from all sections of the embassy, and created a social media committe. But in fact, these resolutions quickly stumbled because of lack of time and resources.

Finally, while evaluation reports about social media (numbers of publications and followers, numbers of reactions - likes, shares) have to be sent to the Canadian Ministry of Foreign Affairs each month, they are not followed by debriefings regarding potential social media upgrading. At the French Embassy, the communication officer establishes a weekly internal document evaluating the online communication of the Embassy. By presenting the number of likes, comments, retweets, etc. of the online messages of the Embassy, the aim is to convince reluctant employees that online communication can have some positive effects. On some occasions, when there are special events - like the visit of a French Minister in Ukraine -, the evaluation of the online communication about the event is much deeper. The communication officer has then to send to Paris a detailed document presenting each article published and the social media performances. Each retweet by Ukraininan officials for exemple, has to be mentioned. Though this report is quite precise and seems as a useful monitoring tool, it is worth noticing that it especially aims at measuring the success of an event on the media stage, but not at perfecting the social media use. Even if some degree of reflexivity is aimed for, from the Ministries point of view in particular, but also from the staff members themselves, it thus seems really hard for the embassy teams to achieve this goal.

\section{CONCLUSION}

The contrasted efforts of embassies studied to develop a presence on social media seems to show that a "public communication contract" (Charron \& Le Cam, 2018 ) - that is "a set of norms, conventions and reciprocical expectations that determine who can talk publicly, of what, when, how, in under what circonstances, by virtue of what title, etc." (Charron \& Le Cam, 2018, p. 13) - is still in creation and has to be carefully scrutinized and understood. Indeed, while these emblematic institutions demonstrate a great care for reinforcing their own institutional usefulness in their host country and addressing local citizens on different scales online, the integration of communication skills and resources appears to be unclear, with limited or inexistent resources devoted to social media. The social media 
"Always There": How Diplomats Deal with Visibility Injunction in the 17 Digital Public Sphere

management tends to be marked by embodiment more than strategy: individual initiatives leading to an account creation or fruitful development that can fade away when the individual leaves for another assignment. But whereas individuals leave, digital traces may not and expectations created by efficient or successful social media campaigns may remain too.

If some digital communication rules have been identified by the actors, such as homemade editorial guidelines depending on the platform used or homemade validation chain processes, diplomats still appear to grope search for the right place to allocate to these communication tasks. Relative freedom and flexibility may finally be an indicator of the place social media communication has in the diplomatic device: a pretty useful yet imponderable way to act publicly.

\section{REFERENCES}

Archetti, Cristina. 2012. "The impact of new media on diplomatic change: An evolutionary model of change." The Hague Journal of Diplomacy 7(2): 181-206.

Bjola, Corneliu, and Marcus Holmes. 2015. Digital diplomacy: Theory and practice. Routledge.

Bjola, Corneliu, and James Pamment, eds. 2018. Countering Online Propaganda and Extremism: The Dark Side of Digital Diplomacy. Routledge.

Charron, Jean, and Le Cam, Florence. 2018. "Le contrat de communication publique? Introduction du dossier Médias, institutions et espace public : le contrat de communication publique." Les Études de communication publique 21:13-17 ["The public communication contract? Introduction to Media, Institutions and public space: the public communication contract." Public Communications Studies $21: 13-17$.

Cull, Nicholas. 2013. "The Long Road to Public Diplkomacy 2.0: The Internet in US Public Diplomacy." International Studies Review 15.1: 123-139.

Criado, J., Ignacio, Rodrigo Sandoval-Almazan, and J. Ramon Gil-Garcia. 2013. "Government innovation through social media." Government Information Quarterly 30.4: 319-326. 
Dodd, Melissa D., and Steve J. Collins. 2017. "Public relations message strategies and public diplomacy 2.0: An empirical analysis using Central-Eastern European and Western Embassy Twitter accounts." Public Relations Review 43.2: 417-425.

Entman, Robert M. 2008. "Theorizing mediated public diplomacy: The US case." The International Journal of Press/Politics 13.2: 87-102.

Fisher, Ali. 2010. "Mapping the great beyond: Identifying meaningful networks in public diplomacy." CPD Perspectives on Public Diplomacy 2: 1-87.

Gilboa, Eytan. 2008. "Searching for a theory of public diplomacy", The annals of the American academy of political and social science 616.1: 55-77.

Glassman, James K. 2008. "Public Diplomacy 2.0: A new approach to global engagement." Remarks to the New America Foundation: 2001-2009.

Gomart, Thomas. 2013. "De la diplomatie numérique", Revue des deux mondes: 131-141. ["Digital Diplomacy." Review of Both Worlds:131-141.]

Huang, Zhao, and Olivier Arifon. 2018. "La diplomatie publique chinoise sur Twitter: la fabrique d'une polyphonie harmonieuse." Hermès, La Revue 2: 45-53. ["Chinese Public Diplomacy on Twitter: Making Harmonious Polyphony." Hermès, The Review 2:45-53.]

Kampf, Ronit, Manor, Ilan and Segev, Elad. 2015. "Digital Diplomacy 2.0: A Cross-National Comparison of Public Engagement in Facebook and Twitter." The Hague Journal of Diplomacy, 10: 331-362.

Khakimova, Leysan F. 2013. "Public diplomacy at Arab embassies: Fighting an uphill battle." International Journal of Strategic Communication 7.1: 21-42.

Kim, Jarim. 2016. "Public relations and public diplomacy in cultural and educational exchange programs: A coorientational approach to the Humphrey Program." Public Relations Review 42.1: 135-145.

Limonier, Kevin, and Maxime Audinet. 2017. "La stratégie d'influence informationnelle et numérique de la Russie en Europe." Hérodote 1: 123-144. ["Russia's Informational and Digital Influence Strategy in Europe." Herodote 1: 123-144.] 
"Always There": How Diplomats Deal with Visibility Injunction in the 19 Digital Public Sphere

Manor, Ilan. 2019. The Digitalization of Public Diplomacy. Springer International Publishing.

Meijer, Albert, and Marcel Thaens. 2010. "Alignment 2.0: Strategic use of new internet technologies in government." Government Information Quarterly 27.2: 113-121.

Nocetti, Julien. 2011. "La diplomatie d'Obama à l'épreuve du Web 2.0." Politique étrangère 1: 157-169. ["Obama's Diplomacy at the Test of Web 2.0." Foreign Policy 1: 157-169.]

Owen, Taylor. 2015. Disruptive power: The crisis of the state in the digital age. Oxford Studies in Digital Politics.

Pamment, James. 2015. "Media Influence, Ontological Transformation, and Social Change: Conceptual Overlaps Between." Development Communication and Public Diplomacy, Communication Theory, 25: 188-207.

Park, Se Jung, and Yon Soo Lim. 2014. "Information networks and social media use in public diplomacy: a comparative analysis of South Korea and Japan." Asian Journal of Communication 24.1: 79-98.

Proulx, Serge, Millerand, Florence and Rueff, Julien. 2010. Web social. Mutation de la communication. Québec : Presses de l'Université du Québec. [Social Web: Mutation of communication, Quebec City: Press of the University of Quebec].

Ricaud, Raphaël. 2018. "Circonvolutions numériques : lorsque la public diplomacy des États-Unis se mettait à l'heure des réseaux sociaux." Politique américaine 1: 31-51. [Digital Convolutions: When US Public Diplomacy gets on the Social Media, American Politics 1: 31-51.]

Seib, Phillip. 2016. The Future of \#Diplomacy. Cambridge: UK. Polity Press.

Sevin, Efe, and Ilan Manor. 2019. "From Embassy Ties to Twitter Links: Comparing Offline and Online Diplomatic Networks." Policy \& Internet. 
Strauß, Nadine, and al. 2015. "Digital diplomacy in GCC countries: Strategic communication of Western embassies on Twitter." Government Information Quarterly 32.4: 369-379.

Su, Shumin, and Mark Xu. 2015. "Twitplomacy: Social media as a new platform for development of public diplomacy." International Journal of E-Politics (IJEP) 6.1: 16-29.

Vergeer, Maurice, and Liesbeth Hermans. 2013. "Campaigning on Twitter: Microblogging and online social networking as campaign tools in the 2010 general elections in the Netherlands." Journal of computer-mediated communication 18.4: 399-419.

Waters, Richard D., and Jensen M. Williams. 2011. "Squawking, tweeting, cooing, and hooting: Analyzing the communication patterns of government agencies on Twitter." Journal of Public Affairs 11.4: 353-363.

White, Candace, and Danijela Radic. 2014. "Comparative public diplomacy: Message strategies of countries in transition." Public Relations Review 40.3: 459465.

Wichowski, Alex. 2015. " "Secrecy Is For Losers" Why diplomats should embrace openness to protect national security", In Digital Diplomacy: Theory and Practice, edited by Corneliu Bjola and Marcus Holmes, 52-70. Milton Park /New York: Routledge.

Wigand, F. Dianne Lux. 2010. "Twitter in government: Building relationships one tweet at a time." Seventh International Conference on Information Technology: New Generations. IEEE.

Yepsen, Erika A. 2012. "Practicing successful twitter public diplomacy: A model and case study of US efforts in Venezuela." CPD Perspectives on Public Diplomacy Paper 6.

Zhang, Juyan. 2013."A strategic issue management (SIM) approach to social media use in public diplomacy." American Behavioral Scientist 57.9: 1312-1331.

Zhong, Xin, and Jiayi Lu. 2013. "Public diplomacy meets social media: A study of the US Embassy's blogs and micro-blogs." Public Relations Review 39.5: 542-548. 